\title{
Putting Beauty at the Heart of the Healing Process
}

Gina Ancora' ${ }^{1}$ Sandra Lazzari ${ }^{2}$, Natascia Simeone ${ }^{3}$

${ }^{1} \mathrm{Head}$ NICU, ${ }^{2}$ Chief Nurse, ${ }^{3}$ NIDCAP Professional

Newborn Intensive Care Unit, Infermi Hospital, Rimini, Italy

$\mathrm{N}$ ewborn babies in the Newborn Intensive Care Unit (NICU) often face physical, emotional and psychological distress. The parents also may experience emotional, psychological and spiritual suffering during this period, affecting their baby's development negatively. Therefore, the baby's development in NICU may be disadvantaged in three ways: their prematurity and the illnesses associated with it, the distress they experienced in the NICU, and the suffering of their parents.

There are two main causes of this distress. First, the use of high technology in the NICU can overwhelm and agitate small and fragile newborns and their parents. Second, hospitals with closed institution philosophies can perpetuate an unsupportive environment for parents. They may be denied ongoing opportunities to be with their newborn(s), as if they were visitors, hindering their emerging parenting skills and identity. This distress may be quite widespread.

How can healthcare systems and professionals address and reduce all this sufferance? Solutions may lie in reimagining how to educate the NICU staff. Specifically, education and support with a focus on the family and their development as well as on the design of the hospital space to be relaxing and individualized.

Each family in the NICU experiences their own unique journey. Humanity and beauty can be found in the stress and grief that many of them face. Grief can often create opportunities and space for sharing, healing and support.

Creating welcoming NICU environments offers opportunities for families to be at the center of the healing process, where they may feel supported and not so alone. Caring for the beauty of the NICU space offers an aesthetic element. It helps to communicate the importance of each person, by caring about them through the natural aspiration to beauty, especially their relationships with a new life. This attention helps to heal parental feelings of helplessness, fragility, resignation and fears of being unable to cope.

The humanizing initiative of putting beauty at the heart of the healing process follows an ongoing cultural change in attitude.

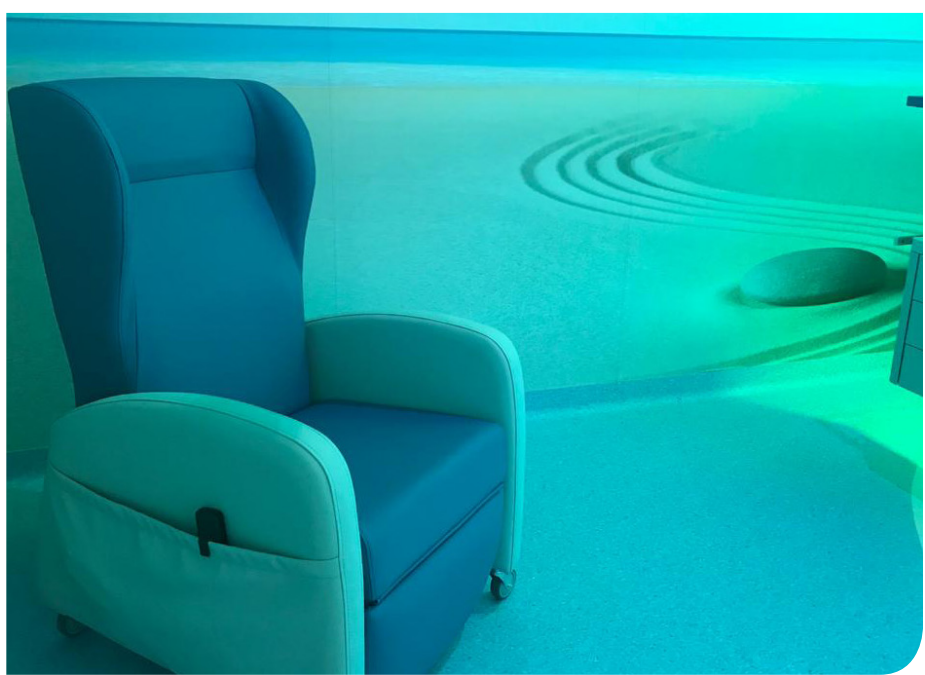

A backlit artistic panel in the NICU in Rimini created with support from the charity La Prima Coccola Onlus.

Each individual is cared for as a whole, including their family, while still considering their delicate stage of development.

Dostoevsky ${ }^{1}$ said "beauty will save the world", and in our case it will help to reduce the stress of the NICU environment for newborn infants and their families. It will produce long term benefits for the neurological, emotional, academic and psychological development of the child.

Important ways to create beauty within NICUs are to design clinical areas to be welcoming with comfortable furniture (both for the baby and their parents), offer pleasant views with natural imagery, use soft and indirect lighting, and maintain low noise levels. Implementing these changes in the care environment has proved to be effective, for example, in reducing the level of pain and the use of painkillers in adults.

In 1948, the World Health Organization (WHO) was already defining wellbeing beyond merely the absence of physical illness, but also in terms of quality of life. This approach in the hospital is complex and requires many skills: clinical, artistic and

\section{Developmental}

\section{Observer}

A semi-annual publication of the NIDCAP Federation International @ 2020. The statements and opinions contained in this newsletter are solely those of the individual authors and contributors and not necessarily of the NIDCAP Federation International. Articles from the Developmental

Observer, duly acknowledged, may be reprinted with permission. Please contact us at: developmentalobserver@nidcap.org.

Senior Editor

Associate Editors

Associate Editor

for Science

Column Editor
Kaye Spence AM

Diane Ballweg, APRN, CCNS, Deborah Buehler, PhD, Sandra Kosta, BA gretchen Lawhon, PhD, RN, FAAN, Maria Lopez Maestro, MD Jeffrey R. Alberts, PhD

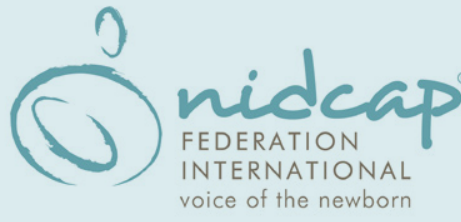

Contributions

We would like to thank all of our individual donors for their generous support of the NFI and its continuing work. 

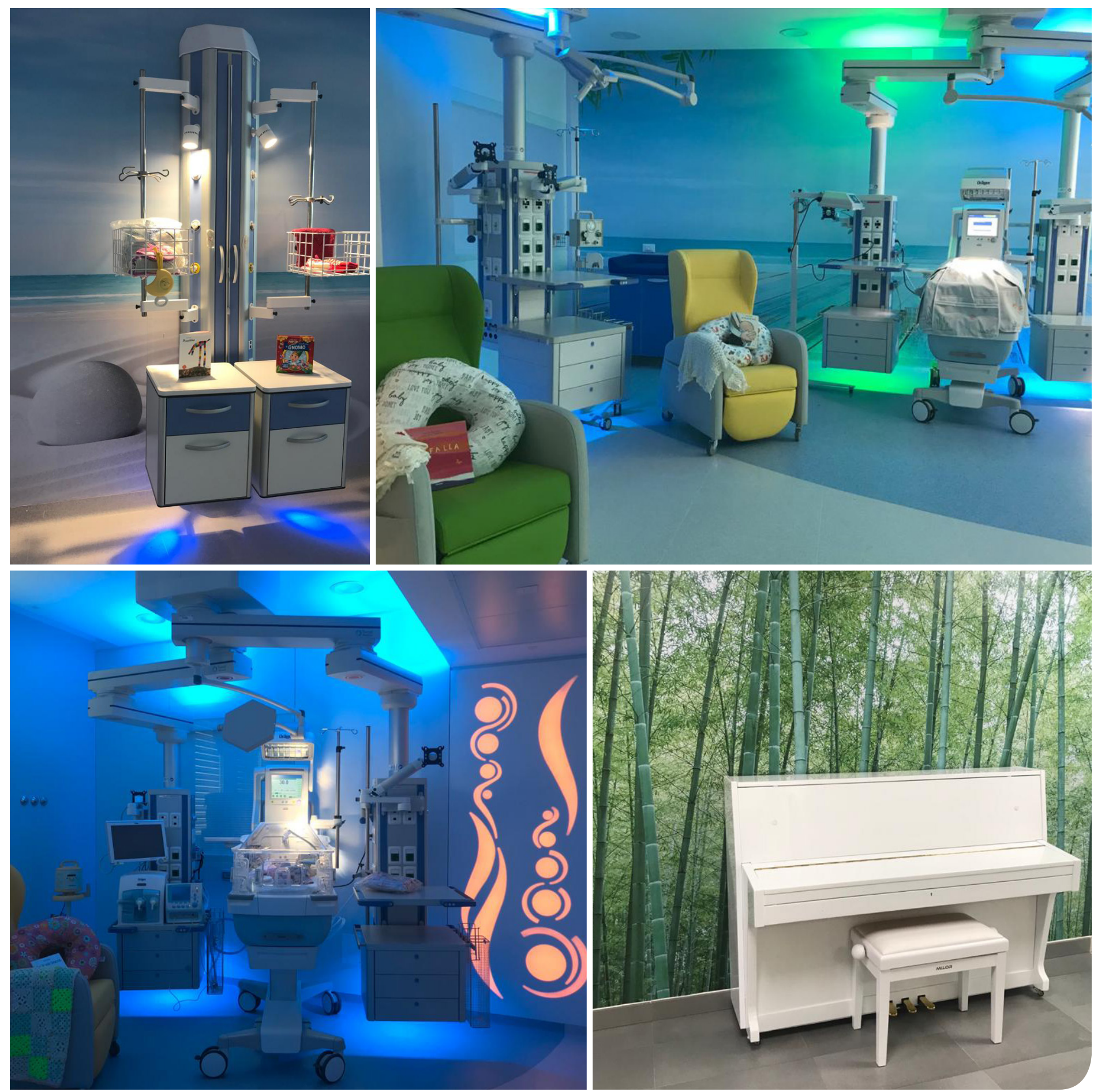

In order to create a more welcoming environment, La Prima Coccola Onlus works to fill the new Rimini NICU with pictorial spaces and backlit artistic panels throughout the clinical areas occupied by the babies and their parents.

technical. The goal of the families that volunteer at "La Prima Coccola Onlus", a charity founded to support the NICU in Rimini with the cooperation of hospital staff, is to draw on the WHO's vision. They work to fill the new NICU with pictorial spaces and backlit artistic panels throughout the clinical areas occupied by the babies and their parents.

Furthermore, work environments that include beauty as a requirement, contribute to the wellbeing of the staff. Being surrounded by beauty encourages an open attitude of listening and increased empathy with the babies and their families, producing positive outcomes and more efficient care.

Reference:

1. Fyodor Dostoyevsky, The Idiot. 